\title{
Experimental macroeconomics: a role-playing experience among bachelor students
}

\section{Lucía Pinar García ${ }^{a}$ and Pau Sendra Pons ${ }^{b}$}

${ }^{\text {a }}$ Department of Economic Analysis, Faculty of Economics (University of Valencia), Avda. de los Naranjos, s/n, 46071, València (lucia.pinar@uv.es), ${ }^{b}$ Department of Corporate, Faculty of Economics (University de Valencia), Avda. de los Naranjos, s/n, 46071, València (pau.sendra-pons@uv.es).

\begin{abstract}
This current innovative education project has the main goal of introducing students to experimental economics to help them better understand complex macroeconomic concepts. For this purpose, it is used an online experimental platform to develop a role-playing dynamic with which students become real economic agents. This gamified technique allows students to interact with each other in the goods and production factors markets and, thus, generate a circular flow studied as one of the main macroeconomic principles. The online platform is conceived as a two-sided website: on one hand, students are assigned a role and asked to make decisions; and, on the other, professors can instantaneously access results in order to explain participants the consequences of their choices.

This innovation had a three-step approach. In the first place, students participated in the internet-based experiment according to the instructions provided by the teaching team. Subsequently, there was a discussion around the main results and their connection with macroeconomic theory. Secondly, students were asked to analyze both the experience and the learning outcomes through a report following well-defined guidelines. Lastly, students evaluated themselves as a co-evaluation practice. This horizontal evaluation promotes students' understanding of the topic due to empathy development and raising awareness of other fellows' efforts.
\end{abstract}

To evaluate the effectiveness of the activity, a survey using a Likert scale was conducted as well as an examination of co-evaluation procedures. Results show high levels of engagement, enhanced motivation due to role-playing and satisfaction due to this gamified experience that raises students' levels of attention by incorporating competition and reward-based mechanisms. Keywords: macroeconomics, experiments, gamification, role playing. 


\section{Introduction}

Economics, just as in the case of other social sciences, has traditionally used mathematical and statistical instruments to model situations based on the interaction between economic agents. Such theoretical models constitute an abstraction of reality that is useful to explain and analyze economic phenomena. However, these mathematical constructions, although valuable and scientifically rigorous, can often distance students from reality and make it difficult for them to learn complex concepts.

In this sense, experimental economics tries to contrast theoretical predictions with human behavior by testing how subjects interact in different real-life situations. Thus, using economic experiments in the classroom helps students to understand the reasoning behind economic agents' decision making (Bardsley et al., 2020; Holt, 2019). This way, students better comprehend the different theoretical arguments that have to be taken into account to make optimal decisions. For this reason, current innovative education project uses economic experiments, a role-playing methodology, with the aim of stimulating students' level of interest by involving them in the learning process as they observe, with their own decisions, the implications of the different theories studied in class.

To do so, we used an experimental setting from Veconlab online platform (University of Virginia) called "Circular Flow Markets" (Chan et al., 2019). It is designed to teach students the classical macroeconomic theory that defines the circular flow of income. After making decisions in the experiment, either as workers or firms, students were able to verify whether an equilibria was reached or not between the market of goods and services and the market of productive factors. In addition, with this project we wanted to involve students in the evaluation process so that they further internalize concepts while being peer-reviewers.

After the theoretical session and the experiment conducted in the classroom, students had to reflect both on the role of experimental economics and the "Circular Flow Markets" experiment. They had to deliver a summary including a personal assessment about experimental economics as a discipline that has gained recognition among researchers over the last decade, as well as an explanation of the experiment, the role of the different economic agents involved and its results. Finally, as it has been mentioned, the project included a peer-review evaluation process to reinforce students' involvement. Results show high levels of satisfaction among students in addition to enthusiasm and interest towards experimental economics and research areas working in this field within the University of Valencia.

The rest of the paper is organized as follows. Section 2 reviews role-playing as an active methodology, gamification and peer-review evaluation. Section 3 explains the different 
phases of the project, from the theoretical lecture on experimental economics to how the experiment and the peer-review evaluation were conducted. Section 4 summarizes findings and, lastly, Section 5 presents the conclusions.

\section{Theoretical framework}

The idea of incorporating the tools of experimental economics into the classroom constitutes a role-playing methodology. The main characteristic of such active teaching techniques is that they are student-centered and emphasize the importance of students' involvement in the learning process, underlying the fact students' engagement has to be achieved through clear and concise explanations about work dynamics as well as by demonstrating the relevance of the proposed activity (Álvarez Rojo, 2013). DeNeve \& Heppner (1997) point out that, in university education, role playing is considered an active learning technique opposed to more passive traditional lectures, since it offers the possibility of combining the acquisition of new knowledge with the improvement of previously acquired knowledge.

There is much research that emphasizes the need to incorporate cutting-edge teaching strategies aimed at promoting effective learning at all educational levels but especially at university level, where the master class has generally been dominant. Thus, David (1997) notes that "games promote or help to promote generalized participation, creating situations in which social conventions are broken; they promote two new roles independently of the traditional participant, that of coordinator and that of observer". On the other hand, Barbato (1999) remarks that "playful activity allows the player to organize ideas in such a way that he or she can extract those considered to be fundamental in order to relate them to other situations, making learning meaningful".

When analyzing role-play in the context of university teaching it is possible to identify specific benefits. Following Schaap (2005, p. 48), these benefits relate to "the promotion of a deep and holistic learning approach that requires students to interact and collaborate in order to complete an assigned task". In this way, role-playing requires students "to adopt different perspectives and to think reflectively about the information represented by the group", thus connecting these benefits to the achievement of meaningful learning in the development of teaching in higher education. In addition, as Porter (2008) states, roleplaying has several motivations for students, among which can be highlighted: assuming different roles, working in teams, empowering decision making together with increased interest and/or commitment to classes. 
Play is a common aspect of human development, which becomes diluted as we grow. In spite of this, the use of recreational activities applied at the university level are particularly important in the learning of attitudes, that is, "subjective experiences of a cognitiveaffective nature, which involve evaluative judgments that are expressed verbally or nonverbally, that are relatively stable and that are learned in a social context", recognizing participatory techniques, such as role-playing or socio-dramas, as effective in developing attitudinal skills (Díaz, 1999). Shaw (2004) suggests that "an ultimate goal of role-playing, which can sometimes be overlooked, is the simple goal of having fun; people tend to remember positive experiences and students tend to retain the lessons they have learned through interactive exercises because of the enjoyment of them. These exercises help to capture the students' attention and are both entertaining and educational".

Therefore, by incorporating the online experiment into the Principles of Macroeconomics course we have introduced the benefits of role playing through the tools of experimental economics. Thus, in addition to bringing students closer to new economic paradigms that move away from the theory of classical rationality, we have stimulated participation and cooperation in class, as well as a peer-review evaluation process by enhancing classroom symmetry.

\section{Methodology}

The innovative education project presented here was carried out for students of the course "Principles of Macroeconomics", a second year subject of the Degree in Finance and Accounting of the University of Valencia. The project was developed in three phases: firstly, the online experiment was carried out in the classroom preceded by an explanation about recent achievements and challenges faced by scholars in experimental economics; secondly, students wrote a report about the experiment, summarizing main findings and providing a personal appraisal on experimental economics' importance; and thirdly, students participated in a peer-review evaluation process that reinforced their involvement through symmetrical evaluation and empathy with others while further consolidating concepts.
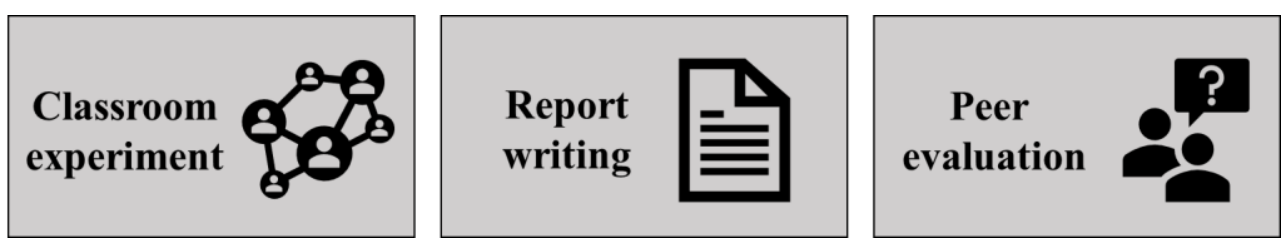

Fig. 1 The three phases of the innovative education project 


\subsection{Classroom experiment}

After revising the theory on one of the main economic indicators, GDP and its relation to employment, the students were introduced to experimental economics with a brief review of the milestones of recent years and the advantages of this tool in social sciences. Then, they accessed the "Circular Flow Markets" experiment on the Veconlab online platform with their own personal computer. The theory of the circular flow of income connects the market of goods and services with the market of productive factors, reflecting that national production can be measured by the income side -retributions of productive factors- or by the consumption side-goods and services acquired to satisfy needs.

The students received printed instructions which, after individual reading, were explained in detail by professors (the game coordinators). At the beginning of the experiment, students were assigned a role: employee or employer. In each round, the employer decides on the salary he offers to the market and the employee decides on the salary he accepts to work at and which will determine his disposable income to be able to purchase goods and services. After ten rounds, students can see the results according to which they receive a monetary reward. In this case, it was substituted by chocolate bars.

\subsection{Report writing}

In order for the students to reflect on the dynamics, we proposed the individual writing of a report that included a personal evaluation of the experience and the effects on the assimilation of the theoretical concepts studied in class. The report was delivered within one week and it was handed in through the Virtual Classroom following certain indications of layout and extension that would harmonize the reports.

\subsection{Peer evaluation}

Once the delivery period was over, we proceeded to the random assignment of reports by the Virtual Classroom for their evaluation. The evaluation criteria were included in the assignment so that this symmetrical evaluation process would not fall into triviality. The peer-review evaluation made up $80 \%$ of the grade, while the remaining $20 \%$ was graded by the teaching staff. It was carried out during the practical class of the subject. 


\section{Results}

To evaluate the effectiveness of the activity, we analyzed co-evaluation procedures by examining grades resulting from the peer-review evaluation. Additionally, we conducted a survey to test overall satisfaction of students using a Likert scale. The latter is intended to provide more specific information on the effectiveness of the methodology used and the areas that need improvement.

\subsection{Peer-review evaluation}

Results of peer-review evaluation show that students, on average, graded others' work with 6.83 points out of 8 . Maximum grade was 8 and minimum one, 5. It demonstrates that, generally, students felt their colleagues have performed high quality tasks. Even the lowest valuation, a 5 out of 8 , was a passing grade. After adding up to two points which correspond to the assessment by the teaching team of the peer-review process, average grade was 8 points, with a maximum grade of 9.50 points and a minimum of 6.25 . Overall, we can observe, both from the peer-evaluation and the teaching team assessment, that students put substantial effort into the requested task. Table 1 summarizes average, maximum and minimum grades for both stages of the evaluation process.

Table 1. Peer-review evaluation and overall grade

\begin{tabular}{cc}
\hline \multicolumn{2}{c}{ Peer-review evaluation (8 points) } \\
\hline Average grade & 6.83 out of 8 points \\
\hline Maximum grade & 8.00 out of 8 points \\
\hline Minimum grade & 5.00 out of 8 points \\
\hline Overall grade (including assessment by professors, 2 points) \\
\hline Average grade & 8.00 out of 10 points \\
\hline Maximum grade & 9.50 out of 10 points \\
\hline Minimum grade & 6.25 out of 10 points \\
\hline
\end{tabular}

\subsection{Overall satisfaction}

Table 2 shows average scores for different questions related to learning outcomes and the experimental methodology. Students, on average, assessed with 4.3 points out of 5 what they had learned from the experiment and with 4.4, their interest in experimental 
economics. Additionally, they assessed with 3.5 points, the lowest grade, how much the experiment had helped them to understand the circular flow of income. Although this grade exceeds the mid-point of the assessment scale, 2.5 , it is quite lower. This might suggest that further experimental sessions might be needed so that students take fully advantage of its usefulness.

Table 2. Assessing learning outcomes and experimental methodology

\begin{tabular}{lc}
\hline \multicolumn{1}{c}{ Question } & $\begin{array}{c}\text { Average } \\
\text { score }\end{array}$ \\
\hline From 1 to 5, assess what you have learned from the experiment. & 4.3 \\
\hline $\begin{array}{l}\text { From 1 to 5, assess how much the experiment has helped you to better } \\
\text { understand the circular flow of income. }\end{array}$ & 3.5 \\
\hline From 1 to 5, assess your interest in experimental economics. & 4.4 \\
\hline
\end{tabular}

Regarding overall satisfaction, taking into account students feel "Principles of Macroeconomics" is a challenging course, it is remarkable that all of them coincide that experiments are useful to understand its dynamics. Students overwhelmingly consider peerreview as a fair evaluation process and claim that they have used objective criterion for their assessments. Findings also suggest students had an active role during the experiment and that it increased their motivation. All of them would like experiments and symmetric evaluation systems to be present in other courses and most of them recognized they got to know the university's experimental economics lab better and could clearly explain what experimental economics is as well as its benefits. Finally, the vast majority said that the playful nature of the methodology used allowed them to learn by playing. 
Table 3. Likert scale: overall satisfaction

\begin{tabular}{|c|c|c|c|c|c|}
\hline Statement & $\begin{array}{c}\text { Strongly } \\
\text { agree }\end{array}$ & Agree & Neutral & Disagree & $\begin{array}{l}\text { Strongly } \\
\text { disagree }\end{array}$ \\
\hline $\begin{array}{l}\text { I consider that "Principles of } \\
\text { Macroeconomics" is a difficult } \\
\text { course. }\end{array}$ & $12.50 \%$ & $62.50 \%$ & $25.00 \%$ & - & - \\
\hline $\begin{array}{l}\text { I believe that experiments are } \\
\text { useful to better understand } \\
\text { macroeconomic dynamics. }\end{array}$ & $75.00 \%$ & $25.00 \%$ & - & - & - \\
\hline $\begin{array}{l}\text { I consider that peer-review } \\
\text { evaluation has been fair. }\end{array}$ & $37.50 \%$ & $37.50 \%$ & $25.00 \%$ & - & - \\
\hline $\begin{array}{l}\text { I have evaluated my colleagues } \\
\text { with objective criterion. }\end{array}$ & $42.86 \%$ & $42.86 \%$ & $14.28 \%$ & - & - \\
\hline $\begin{array}{l}\text { I have actively participated in the } \\
\text { experiment, understanding } \\
\text { increasingly better how it worked. }\end{array}$ & $42.85 \%$ & $28.57 \%$ & $14.29 \%$ & $14.29 \%$ & - \\
\hline $\begin{array}{l}\text { It has increased my motivation } \\
\text { towards the subject. }\end{array}$ & $12.50 \%$ & $62.50 \%$ & $25.00 \%$ & - & - \\
\hline $\begin{array}{l}\text { The teaching team has helped us } \\
\text { at all times. }\end{array}$ & $50.00 \%$ & $37.50 \%$ & $12.50 \%$ & - & - \\
\hline $\begin{array}{c}\text { I would like economic } \\
\text { experiments to be included in } \\
\text { more courses. }\end{array}$ & $75.00 \%$ & $25.00 \%$ & - & - & - \\
\hline $\begin{array}{l}\text { After the session, I got to know } \\
\text { the university's experimental } \\
\text { economics lab better. }\end{array}$ & $25.00 \%$ & $37.50 \%$ & $25.00 \%$ & $12.50 \%$ & - \\
\hline $\begin{array}{l}\text { I can clearly explain what } \\
\text { experimental economics is and } \\
\text { what its benefits are. }\end{array}$ & $25.00 \%$ & $37.50 \%$ & $25.00 \%$ & $12.50 \%$ & - \\
\hline $\begin{array}{l}\text { As a result of the experiment, and } \\
\text { the explanation of the teaching } \\
\text { team, I know the experimental } \\
\text { Nobel Prize winners better. }\end{array}$ & $25.00 \%$ & $25.00 \%$ & $25.00 \%$ & $12.50 \%$ & $12.50 \%$ \\
\hline $\begin{array}{l}\text { I would be interested in learning } \\
\text { more about experimental } \\
\text { economics. }\end{array}$ & $37.50 \%$ & $62.50 \%$ & - & - & - \\
\hline $\begin{array}{l}\text { I would like other subjects to use } \\
\text { more symmetrical evaluation } \\
\text { systems. }\end{array}$ & $25.00 \%$ & $75.00 \%$ & - & - & - \\
\hline $\begin{array}{l}\text { The playful nature of the } \\
\text { experiment allows you to learn by } \\
\text { playing. }\end{array}$ & $50.00 \%$ & $37.50 \%$ & $12.50 \%$ & - & - \\
\hline
\end{tabular}




\section{Conclusions}

Current innovative education project seeks to bring students closer to macroeconomic foundations through economic experiments conducted in the classroom with the aim of making learning more meaningful as students actively participate in the acquisition of new knowledge. Results show both reasonably high grades and overall satisfaction. Although students affirmed macroeconomics is a difficult course, they acknowledged that experiments are useful to better understand macroeconomic dynamics.

Consequently, students reported to have actively participated in the experiment, increasing their motivation towards the subject. Students expressed their desire for more subjects including experiments and symmetric evaluation systems. They also recognized the playful nature of the methodology allowing them to learn by playing. However, this research has limitations. It should be replicated to validate results due to the limited number of students that have participated in this pilot project.

\section{References}

Álvarez Rojo, V. (2013). La enseñanza basada en proyectos (EBPry) "Proyecto-Based Learning". Sevilla: Universidad de Sevilla.

Barbato, M. (1999). El juego es algo serio (pp. 75-85). En C. Pregnam (comp.). Juego, aprendizaje y creatividad. Santiago de Chile: Pontificia Universidad Católica de Chile, Facultad de Educación.

Bardsley, N., Cubitt, R., Loomes, G., Moffatt, P., Starmer, C., \& Sugden, R. (2020). Experimental economics: Rethinking the rules. Princeton University Press.

Chan, S. W., Schilizzi, S., Iftekhar, M. S., \& Rosa, R. D. S. (2019). Web-based experimental economics software: How do they compare to desirable features? Journal of Behavioral and Experimental Finance, 23, 138-160.

David, J. (1997). Juegos creativos para la vida moderna. Lumen.

DeNeve, K., \& Heppner, M. (1997). Role play simulations: The assessment of an active learning technique and comparisons with traditional lectures. Innovative Higher Education, 21(3), 231246.

Díaz, F. (1999). Estrategias Docentes para un aprendizaje significativo: una interpretación constructivista. Bogotá, Colombia: Editorial McGraw-Hill.

Holt, C. A. (2019). Markets, games, and strategic behavior: An introduction to experimental economics. Princeton University Press. 
Porter, M. E. (2008). The five competitive forces that shape strategy. Harvard business review, 86(1), 25-40.

Schaap, A. (2005). Learning political theory by role playing. Politics, 25(1), 46-52.

Shaw, C. M. (2004). Using role-play scenarios in the IR classroom: An examination of exercises on peacekeeping operations and foreign policy decision making. International Studies Perspectives, 5(1), 1-22. 